\title{
Identification and Distribution of Mosquitoes in Kafin Hausa Local Government Area, Jigawa State, Nigeria
}

\author{
Umar Adamu Ahmed ${ }^{1}$, Sani Zakariya ${ }^{2}$ \\ ${ }^{I}$ (Department of Biological Sciences, Sule Lamido University, Kafin Hausa, Jigawa state, Nigeria) \\ ${ }_{2}^{2}$ (Department of Biological Sciences, Sule Lamido University, Kafin Hausa, Jigawa state, Nigeria)
}

\begin{abstract}
Studies were conducted to determine the identity and distribution of mosquito species in Kafin Hausa Local Government Area of Jigawa state, Nigeria. Samples of immature stages where collected from different kinds of breeding sites and reared in cages under laboratory settings until the emergence of fully formed adult mosquitoes. Five species of mosquitoes were morphologically identified. Three mosquito species viz. Culex pipiens, Culex quinquefasciatus and Culex molestus are the most predominant in the area. Aedes aegypti and Anopheles arabiensis were also identified, and constitute only $0.51 \%$ and $0.29 \%$ population respectively. All the species identified were found in man-made breeding sites and are potential vectors of vectors.
\end{abstract}

Keywords: Mosquito, vector, identity, distribution, diseases.

\section{Introduction}

Mosquitoes are well known insects world-wide. They have occupied many niches and altitudes. They belong to the family culicidae with more than 3000 known species distributed among 41 genera (Naz et al., 2014). Most of the common and dangerous mosquito species reported are found in genera Culex, Anopheles and Aedes most of which are ectoparasitic to human, other vertebrates and some invertebrates.

Adult mosquitoes have typically, a slender body which ranges between $3 \mathrm{~mm}$ and $6 \mathrm{~mm}$ in length, a tube-like mouth parts with which they pierce the body of their host. The most effective human-mosquito relationship is their ability to transmit many kinds of pathogenic organisms including protozoans, viruses, bacteria and nematodes leading to various kinds of diseases (William and Pinto, 2012). This takes place in the cause of feeding. The diseases range from various kinds of fever including malaria, dengue and yellow fever, to myasis and lymphatic filariasis (Jackman and Olson, 2012). Each of the reported mosquito-borne disease is species specific leading to the loss of lives thousands of both human and other animals annually (Lock et al., 2012). The distribution of disease carrying vector and the occurrence of the human pathogen are affected by various environmental factors like urbanization, climatic change and the general human behavior (Lock et al., 2012; Naz et al., 2014).

The life cycle of mosquito is almost similar among all species passing through four distinct metamorphic stages of egg, larvae, pupae and adult within an average of 2-3 weeks (William and Pinto, 2012). Female mosquitoes require protein and iron in animal blood to make their egg while male and non-egg laying female mosquitoes naturally feed on nectar and water. In all species of mosquitoes, female laid their eggs in water bodies. The larvae, after hatching swims, feed on microorganisms and periodically cast-off their skin in order to grow. The larvae metamorphose into pupae and subsequently the adult emerges and fly away. Periodic fluctuations in mosquito populations have been observed during different annual seasons. Each species has its own distinct habitat and behavioral preferences (Muturi et al., 2008; William and Pinto, 2012). These preferences range from biting periods to hosts. But availability of breeding sites is a common denominator among all species of mosquitoes (Jackman and Olson, 2012).

Several efforts are being made to reduce the menace caused by mosquito worldwide. These range from cultural, mechanical, ecological control to use of natural and synthetic chemicals (Fang, 2010; Jackman and Olson, 2012). More recently is the genetic manipulations, either through RNA interference or development of sterilized male mosquitoes (Fang, 2010).

The recent outbreak of mosquito borne disease in the Northwestern region of Nigeria shows the need for better knowledge of taxonomy and functional diversity of mosquito species in the region because development of mosquito inventory is an integral part of disease surveillance and will provide an idea on how better to come about the diseases they transmit. The purpose of this study is to determine the identity and distribution of mosquito species within Kafin Hausa Local Government of Jigawa State, Northwestern Nigeria, through collection and rearing of immature stages. 


\subsection{Study Area}

\section{Methodology}

The study was carried out in Kafin Hausa Local Government Area of Jigawa State, Northwestern part of Nigeria. The area is located between latitude $12^{\circ} 68^{\prime} \mathrm{N}$ and longitude $10^{\circ} 26^{\prime} \mathrm{E}$. It falls within the Sudan savannah zone with a temperature and Annual rainfall ranges of $15.86-38^{\circ} \mathrm{C}$ and $491-1186 \mathrm{~mm}$ respectively. Kafin Hausa has an estimated human density of $223.91 \mathrm{~km}^{-2}$. The main occupations of the people in the area are farming, trading and animal grazing. UNESCO (2012) have estimated that $85 \%$ of people in Jigawa live in rural areas with $24.2 \%$ literacy level as at 2012 .

\subsection{Study Period}

The period for sample collection was between the months of March and May, 2017. It was a dry period characterized with high temperatures ranging between $20^{\circ} \mathrm{C}$ in the evening hours and $38^{\circ} \mathrm{C}$ during the day. The mosquito potential breeding sites during this period were restricted to deep domestic discharge drainages, abandoned water tanks, wells and rice fields.

\subsection{Collection and Rearing of Immature Stages}

Immature stages (larvae and pupae) of mosquito were collected at various kinds of potentially identified mosquito breeding sites. These sites were found distributed in the four randomly selected locations within Kafin Hausa Local Government Area. The locations visited for sample collection were Bulangu, HagoTage, Ruba villages and Kafin Hausa Town. Mosquito larvae/Pupae were collected using scoop method following Gilles and De Meillon (1968), and William and Pinto (2012) with some modifications. Larvae/pupae were scooped from rice fields using soup ladle together with water they are living in and placed in a well labeled, transparent, four-liter plastic buckets. Buckets were covered with bed net $(1 \mathrm{~mm} \times 1 \mathrm{~mm})$ held in place with a rubber bands to allow ventilation. The procedure was repeated for drainages, water tanks. Samples from wells were drawn with a large iron buckets, allowed to rest before the scoops were made. Four scoops were made from each of the breeding sites. Samples were taken to Biology Laboratory, Sule Lamido University for rearing to adult stages.

Buckets containing the immature mosquitoes were placed in side separate rearing cage $(\operatorname{lmx} 0.5 \mathrm{mx} 0.5 \mathrm{~m})$ placed on sheets of white cloth for easy recognition of dead mosquitoes. The net covers were removed before they were placed in the cages this allows proper management and feeding. The larvae were fed twice daily with an appropriate amount of ground fish diet (Ahmed and Sani, 2016; William and Pinto, 2012). The process continued until the emergence of fully developed adult mosquitoes. Emerged adults were prevented from escaping by bed net around the cages.

\subsection{Preservation and Morphological Identification of Adult Mosquitoes}

Emerge adult mosquitoes were knocked-out with light pyrethrin spray against the net. Mosquitoes were later picked and transferred into Eppendorf tubes containing silica gel using soft brush. Tubes were labeled according to the dates of collection and locations (Gilles and De Meillon, 1968; William and Pinto 2012).

Identification was restricted to adult mosquitoes. Preserved mosquitoes were identified with the aid of stereo-microscope following the identification guide by Gillett, (1972), and Gilles and Coetzee (1987). Mosquitoes were first categorized based on their genera and subsequently on species.

\subsection{Data Analysis}

Only the adult mosquitoes obtained by rearing stages in the laboratory were used for analysis. Data were presented in percentages. Species abundance was determined in percent as the number of species per cluster out of the total number of mosquitos collected following Naz et al. (2014) and Dalhatu et al. (2016).

\section{Result}

Identification of mosquito species was restricted to adult stages only. Fig. 1 below shows the total number of mosquitoes collected in percent per breeding site per collection area in Kafin Hausa Local Government Area. Highest population of mosquitoes was collected in drainages in all the locations where collections were made. This was followed by mosquito population in abandoned water tanks. Hundred (100\%) percent of the mosquito in Kafin Hausa town was collected from drainage. Only $0.56 \%$ population of mosquito was found in well water in Bulangu village. No $(0.00 \%)$ mosquito were collected from wells in Hago-Tage, Ruba and Kafin Hausa Town (Figure 1). Sixteen (16.00\%) percent of immature mosquitos in Hago-Tage were collected from rice field. 


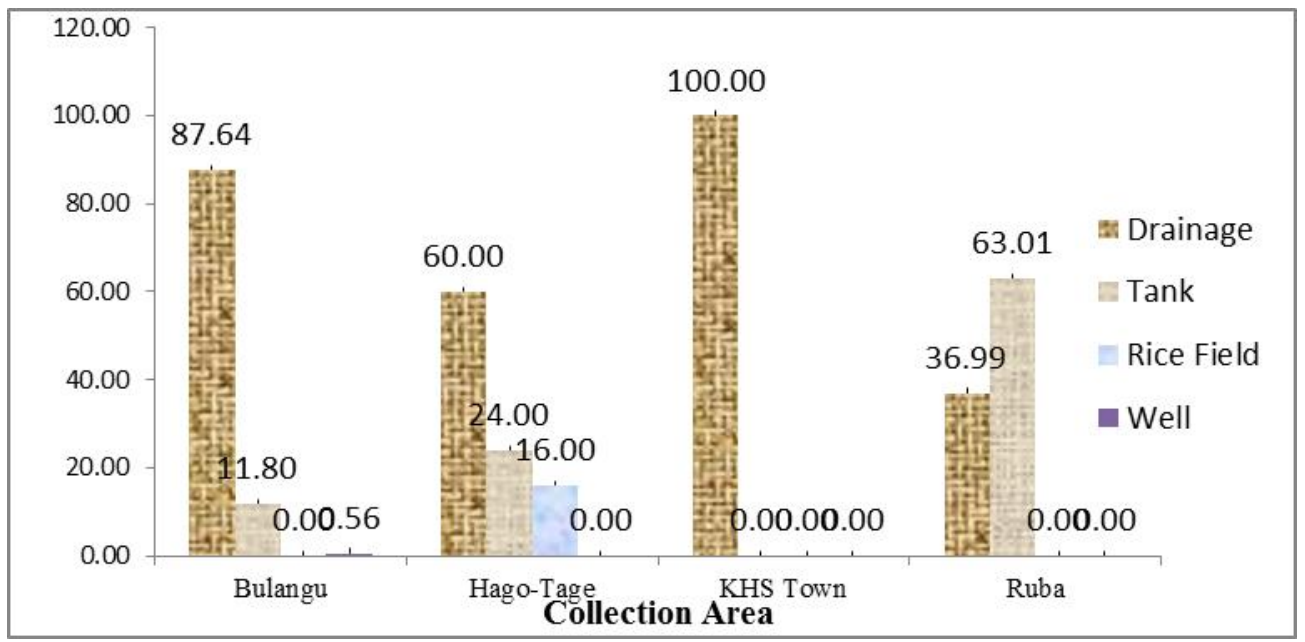

Figure 1 Population of mosquitoes collected per breeding sites

Table 1 below shows the identity of mosquito species collected from various locations within Kafin Hausa Local Government Area. The study shows that while Culex quinquefasciatus was identified in all areas visited for sample collection within the Local Government Area, the species Aedes aegypti and Anopheles arabiensis where observed only in Bulangu and Hago-Tage areas of the local government (Table 1).

Table 1 Mosquito species identified per Collection Area in Kafin Hausa Local Government Area.

\begin{tabular}{|l|c|c|c|c|}
\hline & \multicolumn{4}{|c|}{ Collection Area } \\
\hline Mosquito Species Identified & Bulangu & Hago-Tage & Kafin Hausa & Ruba \\
\hline Culex quinquefasciatus & + & + & + & + \\
\hline Culex molestus & + & + & + & - \\
\hline Culex pipiens & + & - & + & + \\
\hline Aedes aegypti & + & - & - & - \\
\hline Anopheles arabiensis & - & + & - & - \\
\hline
\end{tabular}

Note: "+ and -" indicates the presence and absence of mosquito species respectively.

Fig. 2 below shows the mosquito species distribution in Kafin Hausa Local Government Area. Highest number of mosquito population identified belonged to the genus Culex. The highest population (42.86\%) was recorded by Culex pipiens, followed by $C x$. quinquefasciatus (40.00\%) and Cx. molestus (16.34\%).

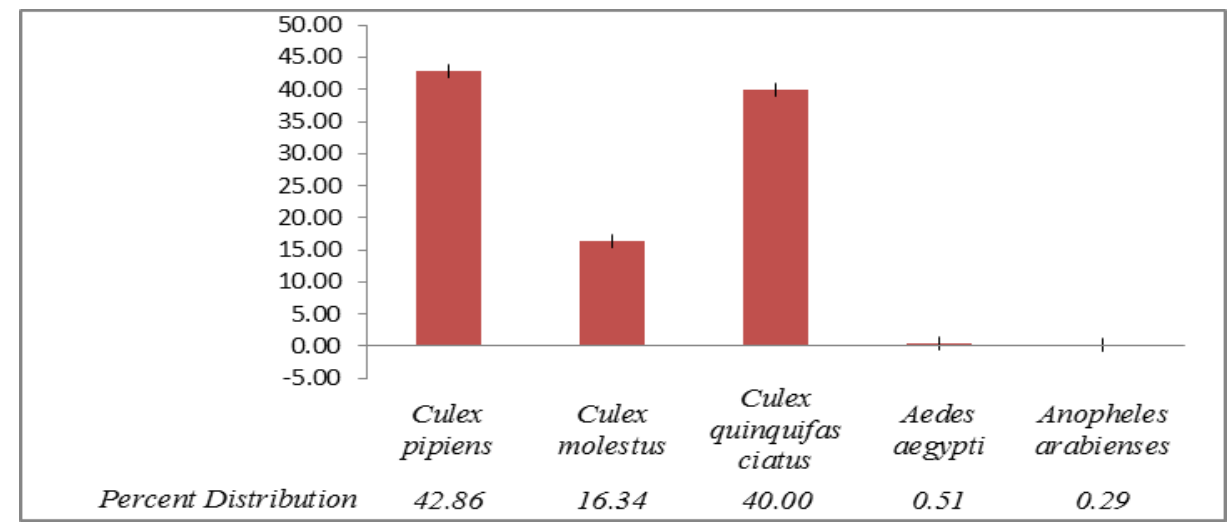

Figure 2 Distribution of Mosquito species in Kafin Hausa Local Government Area, Jigawa State, Nigeria.

\section{Conclusion}

This study was aimed at determining the diversity and distribution of mosquito species in Kafin Hausa Local Government Area of Jigawa state, Nigeria. Five (5) species of mosquito were identified in the studies, all of which are potential vectors of diseases. The study showed three species of Culex (Culex quinquefasciatus, Cx. pipiens and $C x$. molestus) mosquitoes are predominant in the area. Most of these species were reported in mosquito studies in the neighboring Local Government Areas (Ahmed and Sani, 2016; Dalhatu et al., 2016) and elsewhere in Nigeria (Umaru et al., 2006; Bunza et al., 2010; Yayock et al., 2014). All of the identified species breed in man-made breeding sites such as drainages, rice fields, tanks and wells. T`he diversity and abundance of the mosquito species may be related to the availability of breeding sites in the area studied. Muturi et al. (2008) reported that the population of immature stages of Anopheles arabiensis and Culex quinquefasciatus in their habitat are affected by availability of food and dissolved oxygen. 


\section{Acknowledgments}

The Authors wish to acknowledge the management of Sule Lamido University, Kafin Hausa for sponsoring the entire research. Also, Mr Hafiz M. I. Anas H. and Musa, A. of the Laboratory Section, Department of Biological Sciences, Sule Lamido University, Kafin Hausa for technical support.

\section{References}

[1] Naz, R., Maryam, A. and Shabnam. Population Dynamics of Mosquitoes in Various Breeding Habitats at University of Peshawar Campus, Khyber Pukhtunkhwa Pakistan. Journal of Entomology and Zoology Studies, 2 (2), 2014, 189-195.

[2] William, J and Pinto, J. (2012). Training Manual on Malaria Entomology for Entomology and Vector Control Technicians (Basic Level). RTI International. Pp11-48.

[3] Jackman, J. A. and Olson, J. K. (2012) Mosquitoes and the diseases they transmit. Agricultural Communicatons, The Taxas A\&M University System. http://insects.tamu.edu. April, 2017.

[4] Lock, K., Dekoninck, W., Adriaens, T and Goethals P. I. M. Distribution and ecology of mosquito larvae (Diptera:Culicidae) in Flanders (Belgium). Belgium Journal of Zoology, 142(2), 2012, 138-142.

[5] Muturi, E. J., Mwangangi, J., Shililu, J., Jacob, B. G., Mbogo, C., Githure, J., and Novak, R. J. Environmental Factors Associated with the Distribution of Anopheles arabiensis and Culex quinquefasciatus in a Rice Agro-ecosystem in Mwea, Kenya. Journal of Vector Ecology, 33(1), 2008, 56-63.

[6] Fang, J. A world without mosquitoes. Nature, 466(22), 2010, 432-434

[7] United Nations Educational, Scientific and Cultural Oranization, UNESCO (2012). High Level International Round Table on Literacy "Reaching the 2015 Literacy Target: Delivering on the Promise" Action Plan. Paris.

[8] Gillies, M. T. and De Meillon, B. (1968). The Anophelinae of Africa south of the Sahara (Ethiopian Zoogeographical region). South African Institute for Medical Research, Johannesburg, South Africa, 54.

[9] Ahmed, U. A. and Sani, Z. Studies of Mosquitoes in Hadejia Emirate, Jigawa State, Nigeria. Proceedings of the Academic Conference on Positioning Sub-sahara Africa for Development in the New Development, 9(1), 2016,1-12.

[10] J. D. Gillett, Common african mosquitoes and their medical importance. First Edition. (London, UK: John Swain and Co. Ltd. 1972).

[11] Gillies, M. T. and Coetzee, M. (1987) A Supplement to the Anopheles of Africa South of Sahara. The South African Institute of Medical Research, Johannesburg, South Africa. Pp 12-79.

[12] Dalhatu A., Omar, A. A. and Bagari H. Surveillance of Mosquito Species Abundance and Composition in Azare, Katagum Local Governement of Bauchi State, Nigeria. Journal of Pharmacy and Biological Sciences, 11(6), 2016, 105-109.

[13] Umaru, N. F. Akogun, O. B. and Owuwama, C. I. Species Identification of Anopheles and Culex Mosquitoes and Its Epidemiological Implications in Yola, Nigeria. Nigerian Journal of Parasitology, 27(1), 2006, 22-31.

[14] Bunza, M.D.A. Suleiman, A. A. Yusuf, A. M., Bala, A. Y. Relative Abundance of Mosquito Species in Katsina Metropolis, Katsina State, Nigeria. Nigerian Journal of Parasitology, 31(2), 2010, 73-78.

[15] Yayock, H. C. Ndams, I. S., Kogi, E, Ahmed, A. B. and Vagime, C. G. (2014). Distribution of Mosquito Species in Kaduna, Metropolis, Kaduna State, Northern Nigeria. Nigerian Journal of Entomology, 31, 2014,15-21. 